\title{
Use of hyaluronic acid fillers for the treatment of the aging face
}

\author{
Michael H Gold \\ Gold Skin Care Center, Tennessee \\ Clinical Research Center, Nashville, \\ TN, USA; Department of Medicine, \\ Vanderbilt University Medical \\ School,Vanderbilt University Nursing \\ School, Nashville, TN, USA; Huashan \\ Hospital, Fudan University, Shanghai, \\ China
}

\begin{abstract}
Hyaluronic acid fillers have become popular soft tissue filler augmentation agents over the past several years. They have helped revolutionize the filler market with a number of new products available for use for our patients. The purpose of this manuscript is to review the characteristics of the HA fillers and to review each of the current products currently available for use in the US.
\end{abstract}

Keywords: hyaluronic acid, fillers, soft tissue augmentation, expression lines, aging face, collagen

\section{Introduction}

The last several years have seen a number of new soft tissue augmentation products (to be commonly called "fillers") emerge into the armamentarium of products used by physicians in the treatment of the signs of aging. These products have become increasing popular since the advent of the use of botulinum toxin, type A, for the treatment of expression lines, mainly of the upper one third of the face. In fact, in a recent survey conducted by the American Society for Aesthetic Plastic Surgery (ASAPS), the number one non-surgical procedure being performed currently in the US is the injection of botulinum toxin, type A, whereas the fifth most common procedure is now the injection of hyaluronic acid (HA) fillers, the topic of this manuscript. ASAPS data currently rank the injection of botulinum toxin number one, laser hair removal number two, chemical peels number three, microdermabrasion number four, and HA fillers number five. The numbers also represent a 12.3\% increase over the use of bovine and human collagen treatments over the previous year and approximately $48 \%$ of all dermal filler procedures being performed (www.surgery.org/public).

The hallmark of the aging face is loss of associated subcutaneous volume over time. Clinically, with this loss, one commonly finds the signs most clinicians see routinely when confronted with a patient concerned with the aging face - an increase in facial vasculature and pigment alterations, as well as an increase in the lines and wrinkles of the skin. This is associated histologically with a thinning of the epidermis and with dermal atrophy and loss of the elastic tissues present within the dermis and with actinic changes with loss of dermal collagen. The treatment for this change over time can be multiple, from skin care products, to energy based therapies (lasers, light sources, and radiofrequency devices) to fillers and toxins. HA fillers play an integral part in the correction of changes associated with aging; especially those associated in the lower one-half of the face, from the nasolabial folds, to the vertical lip lines of the lips, the marionette lines around the mouth, and in the thinning of the lip itself. They also can be used for volume enhancement of the cheeks.

The concept of an ideal filler has been debated for a number of years. Without question, everyone wants the ideal filler to be easy to inject, produce reproducible 
results, and have longevity (lasting between 1 and 2 years). Further, the ideal filler would be painless on injection and nonallergenic (no skin tests required), noncarcinogenic, nonteratogenic, and we would expect it not to migrate once injected into the skin. We would like the ideal filler to be stored at room temperature, have a long shelf-life, and be free from all transmittable diseases. Further, we would want this ideal filler to have few, if any local adverse events, and be affordable to both the patient and the physician. And finally, we want the material to last, with a debate still ongoing between those fillers which are temporary and those fillers which are permanent. It is beyond the scope of this document to pursue further the temporary versus permanent debate. We are closer than ever with the advent of the HA fillers.

\section{Zyderm $^{\circledR}$ and Zyplast ${ }^{\circledR}$}

In order to understand the HA fillers and their prominent role in the marketplace, we must spend a little time reviewing the past and some of the other filler products on the market. The first synthetic group of fillers was the bovine derived collagen products, namely Zyderm ${ }^{\circledR}$ and Zyplast ${ }^{\circledR}$ collagen. The collagen material was derived from a closed herd of cattle and purified for human use. All of the collageninjectable materials contain lidocaine, to ease any associated pain which may be associated with the injection technique. Zyderm ${ }^{\circledR}$ I, first approved by the FDA in 1981 , is a $3.5 \%$ by weight bovine dermal collagen, in a suspension of phosphatebuffered physiologic saline. Zyderm ${ }^{\circledR} \mathrm{I}$ is recommended for injection into the superficial papillary dermis and was approved for the treatment of superficial lines and wrinkles as well as shallow acne scars. Zyderm ${ }^{\circledR}$ II, FDA approved in 1983 , contains $6.5 \%$ by weight bovine dermal collagen in a similar buffered saline suspension. Most clinicians felt this material was best used to treat acne or traumatic scars on the face, although it worked well for lines and wrinkles, too. Its injection should be into the papillary dermis. Zyplast ${ }^{\circledR}$, FDA approved in 1985 , is a $3.5 \%$ by weight bovine dermal collagen cross-linked with glutaraldehyde, making it more resistant to biodegradation after injection. Zyplast ${ }^{\circledR}$ is best injected into the mid-deep dermis and its recommended use is for deep lines and folds (Narins and Bowman 2005; Eppley and Dadvand 2006).

Overcorrection of the defect is necessary with both of the Zyderm ${ }^{\circledR}$ products because of the buffered saline contained within the syringes. Because of the animal nature of the material, it was necessary to perform intradermal skin testing prior to the injection procedure. From early studies, it became clear that double skin testing, that is, skin testing on each forearm 4 weeks apart, reduced the apparent risk of allergy or hypersensitivity to a very small percentage. Still, even with double skin testing, approximately $3 \%$ of patients treated may develop hypersensitivity to the bovine collagen. Other adverse events, which are reported, include local effects such as erythema, induration, and pruritus at the injection sites. More rare side-effects have included granuloma formation and necrosis secondary to vascular occlusion. It was also realized that, although the standard injectable materials from the early 1980s up until the end of the 1990s, these materials were variable in their longevity, with most clinicians noting an approximate 3-month duration with the collagen products.

\section{CosmoDerm $^{\circledR}$ and CosmoPlast ${ }^{\circledR}$}

Primarily because of the Zyderm ${ }^{\circledR} /$ Zyplast $^{\circledR}$ hypersensitivity concerns, human-derived collagen products were developed, known as CosmoDerm ${ }^{\circledR}$ and CosmoPlast ${ }^{\circledR}$. These products were both FDA approved in 2003 for use in facial aesthetic surgery with the hope of decreased potential immunogenicity and longer lasting clinical results. These are the only filler materials available which are derived from human collagen - a single cell line of human fibroblasts that has over 10 years of use in manufacturing of human based tissues used in a variety of medical disciplines. CosmoDerm ${ }^{\circledR}$ is used in a similar fashion as Zyderm ${ }^{\circledR} I$ and CosmoPlast ${ }^{\circledR}$, similar to Zyplast $^{\circledR}$. Immunogenicity studies have shown a marked decrease in potential hypersensitivity reactions (less than $1.3 \%$ ); however, most clinicians, hoping for longer-lasting collagen fillers, are convinced that the duration of these are similar to the earlier collagen products, Zyderm ${ }^{\circledR}$ and Zyplast ${ }^{\circledR}$ (Mentor Corporation 2006).

\section{HA fillers}

In the US, physicians were "content" using US collagenbased products for the treatment of lines and wrinkles, folds, and furrows associated with the aging face throughout the 1980s and the 1990s. In Europe, however, a revolution was taking shape, with products being developed that would soon change how the majority of US doctors would utilize fillers for our patients. This revolution began with the development of the HA fillers, the topic of the remainder of this manuscript.

A number of HA fillers are available in the US for use as filler materials; many more are under development process at the time of writing. Table 1 lists the HA fillers that are available and/or are under development. In order to fully understand the scope of HA fillers, and to determine which 
Table I Hyaluronic acid (HA) fillers available and under clinical study in the US

\begin{tabular}{ll}
\hline Currently available & Under clinical study \\
\hline Hylaform $^{\circledR}$ & Restylane $^{\circledR}$ Perlane \\
Hylaform $^{\circledR}$ Plus & Restylane $^{\circledR}$ Fine Lines \\
Captique $^{\text {TM }}$ & Puragen $^{\text {TM }}$ Plus \\
Restylane $^{\circledR}$ & Belotero \\
Juvederm $^{\text {TM }}$ Ultra & \\
Juvederm $^{\text {TM }}$ Ultra Plus & \\
\hline
\end{tabular}

HA filler may be best for a particular patient, a review of the basic characteristics and terms are necessary. HA, or hyaluronan, by definition, is a glycosaminoglycan which consists of regular repeating non-sulfated disaccharide units of glucuronic acid and $\mathrm{N}$-acetylglucosamine (Alberts et al 2002). HA is a naturally occurring substance, a biopolymer, which exhibits no species and no tissue specificity. HA is an essential component of the extracellular matrix of all animal tissues and is an abundant component of this matrix. HA is highly hydrophilic, that is, it attracts water, and this helps it form large concentrations that can occupy a large volume relative to its mass. It has been shown to form gels at even low concentrations. When water is drawn into the HA matrix, it has been shown to create a swelling pressure or turgor that enables the HA complex to withstand compressive forces. Thus it has been found useful as a filler in treating some of the signs of aging. The fact that HA exhibits no tissue or species specificity is crucially important to minimize any untoward effect for potential immunologic reactions or transplantation rejection. The first HA developed as a dermal filler was in 1989 by Balazs (Balazs and Denlinger 1989), who understood the biocompatibility of this class of compounds and lack of immunogenicity. The product was not long lasting, but the revolution had begun.

The main differentiators for HA fillers are: source of HA; concentration of HA in each syringe being utilized; the particulate size of the HA; whether the HA is cross-linked; the type of cross-linking agent used in the HA; whether the HA is monophasic or biphasic; and whether there is an anesthetic in the HA syringe. The HA source for the available fillers are either avian, that found primarily in rooster combs, or from bacteria-sourced HA, mainly from the synthetic fermentation of the Staphylococcus equine bacterium. This latter source has become more popular recently because of potential allergy to the avian source owing to a high avian protein content, and because the bacterial-derived HA products are more pure, more viscous, and not derived from an animal source. The concentration of HA fillers is also important.
Those HA fillers with higher HA concentrations displace more tissue and are felt to equate to longer duration of effect. Those HA fillers with concentrations of $20 \mathrm{mg} / \mathrm{g}$ or more of HA are now considered ideal. All HA fillers utilize a single ether cross-link bond to stabilize the product. The newer non-particulate HA fillers are either double cross-linked, multi crossed-linked, or monophasic gels. They are crosslinked with a single ether bond and have their long chains of HA bound to 1,4-butandiol diglycidylether (BDDA) as well as having the shorter HA chains bound to the network, also with BDDA. The resulting homogeneous mass becomes potentially less resistant to degradation, making for a longerlasting HA filler. As a result of these processes, and because these newer gels are non-particulate in formation, they require a higher HA concentration for the duration of effect. The cross-linking of HA is required to prevent biodegradation from free radicals and enzymes and to increase the HA filler duration. BDDA, as already mentioned, has been utilized with much success. A newer agent, 1, 2, 7, 8-diepoxyoctane, may further enhance duration. Larger HA particles tend to last longer and are usually used for deeper dermal injections and defects. Monophasic HA fillers are cohesive gels rather than just HA particles. Biphasic HA fillers are made into particle form. Each form has proponents - monophasic HA fillers may last longer and may not migrate after injection; biphasic HA fillers can be customized to particle size per indication and anatomic area being treated (Medical Insight Inc 2006).

\section{Hylaform $^{\circledR}$}

Hylaform $^{\circledR}$ was the first of the HA fillers available for use in the US. It was developed by Genzyme Biosurgery (New Jersey, US) and was distributed by Inamed ${ }^{\circledR}$ (Santa Barbara, CA, US) before Inamed's acquisition by Allergan, Inc. (Irvine, CA, US) in 2006. Hylaform ${ }^{\circledR}$ was FDA approved in April, 2004. Hylaform ${ }^{\circledR}$ is a sterile, colorless gel implant material, cross-linked with divinyl sulfone, and derived from an avian source, that from the rooster comb. The degree of cross-linking is $20 \%$. The HA concentration in Hylaform ${ }^{\circledR}$ is $4.5-6.0 \mathrm{mg} / \mathrm{mL}$ and the gel particle size is 500 um. Hylaform ${ }^{\circledR}$ is indicated for the treatment of moderate to severe facial wrinkles and folds. It is not recommended for lip enhancement or augmentation. Skin testing with this material is not required. Its major disadvantage is longevity, as most would submit that Hylaform ${ }^{\circledR}$ results generally last 3-4 months. A second Hylaform ${ }^{\circledR}$, Hylaform ${ }^{\circledR}$ Plus, is also FDA approved (October 2004), for mid to deep dermal injection to treat moderate to severe facial wrinkles and folds. 
It also is derived from an avian source, again rooster combs. Its cross-linking agent is also divinyl sulfone, with a $20 \%$ degree of cross-linking. The HA concentration of Hylaform ${ }^{\circledR}$ Plus is also $4.5-6.0 \mathrm{mg} / \mathrm{mL}$ but the particle size is increased, to $750 \mathrm{um}$. Unfortunately, longevity with this product too is in the 3- to 4-month range. Local adverse reactions with the product are not usually significant, a benefit for those requiring a "quick fix" type of procedure (Manna et al 1999; Monheit 2004). A clinical example of the use of Hylaform ${ }^{\circledR}$ is found in Figure 1.

\section{Captique $^{\text {TM }}$}

The second FDA-cleared HA filler is known as Captique (Genzyme, Inamed, Allergan; now Mentor Corporation, Santa Barbara, CA, US). It was developed utilizing Genzyme's proprietary non-animal stabilized HA technology. This averted the potential immunological problems associated with the previous avian source for the HA fillers. It received FDA clearance in December, 2004. It is cross-linked with divinyl sulfone, is $20 \%$ cross-linked, contains $4.5-6.0 \mathrm{mg} / \mathrm{mL}$ $\mathrm{HA}$, and a gel particle size of $500 \mu \mathrm{m}$. It is a clear, colorless gel that has its indication for fine lines and wrinkles of the face. Skin testing is not required prior to its injection. The duration of effect is typically felt to be anywhere from 3 to 6 months (Matarasso et al 2006). An example of Captique ${ }^{\mathrm{\tau M}}$ is shown in Figure 2.
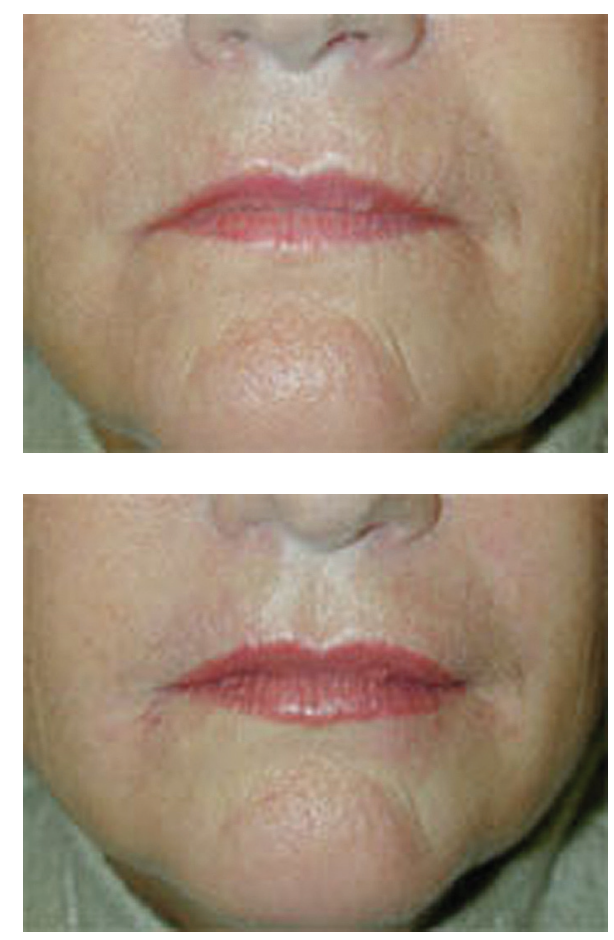

Figure I A clinical example of the use of Hylaform ${ }^{\circledR}$ for lip augmentation.


Figure 2 A clinical example of the use of Captique ${ }^{\text {TM }}$ for nasolabial folds.

\section{Restylane ${ }^{\circledR}$}

The next of the HA fillers approved for use in the US was Restylane $^{\circledR}$, FDA approved for use in December, 2003. It is manufactured by Q-Med (Upsalla, Sweden) and is marketed in the US and Canada by Medicis, Inc. (Scottsdale, AZ, US). Restylane ${ }^{\circledR}$ is a non-animal stabilized HA, known as NASHA, produced from the fermentation of equine streptococci. It is cross-linked with BDDA, with a $1 \%$ degree of cross-linking. The HA concentration of Restylane ${ }^{\circledR}$ is $20 \mathrm{mg} / \mathrm{mL}$ and its gel particle size is $400 \mu \mathrm{m}$. Restylane ${ }^{\circledR}$ has a particulate size of 100,000 gel particles per milliliter and is the only HA filler in this family approved in the US at the time of this writing. Its FDA approval is for mid-dermal applications such as deep wrinkle correction, lip augmentation, nasolabial fold correction, and for glabellar creases. Restylane ${ }^{\circledR}$ has also been used with success in the treatment of tear trough deformities. Other Restylane ${ }^{\circledR}$ products available in other countries and in clinical testing in the US include Restylane ${ }^{\circledR}$ Perlane $^{\circledR}$ (8000 gel particles $/ \mathrm{mL}$ ) for deeper injections and deeper defects, and Restylane ${ }^{\circledR}$ Fine Lines $(200,000$ gel particles/mL) for superficial injections and superficial defects (Matarasso et al 2006).

The use of Restylane ${ }^{\circledR}$ in clinical trials date back to the 1990s. In two separate European studies, by Duranti et al (1998), and Olenius (1998), duration of effect were evaluated and found to be $78 \%$ maintaining moderate to marked improvement at 8 months in the study by Duranti; 
and $82 \%$ and $69 \%$ correction after 12 weeks and 26 weeks respectively in the study by Olenius. Both of these studies reported injection-related reactions, including treatmentsite erythema, hyperpigmentation at the treatment site, and pain from the injection itself of about 13\%. Further analysis and study of injectors from Europe in 1999 yielded an improvement in adverse events, with only $0.15 \%$ of patients experiencing localized cutaneous reactions (Friedman et al 2002). Several cases of delayed implant hypersensitivity were reported in the European experience $(0.4 \%-3.7 \%)$ prompting the manufacturers to introduce a more purified product in 1999 (Lowe et al 2001; Lupton et al 2001; Micheels 2001). Further evaluation from the European groups showed that with the new purified product, adverse events were reduced to $0.06 \%$ and hypersensitivity reactions were reduced to $0.02 \%$. From this experience and low incidence of hypersensitivity reactions, no skin testing is required for the Restylane ${ }^{\circledR}$ available in the US.

The pivotal US clinical trial from Narins et al (2003), compared Restylane ${ }^{\circledR}$ in one nasolabial fold with Zyplast ${ }^{\circledR}$ collagen in the other fold. The study utilized 138 predominantly female and Caucasian individuals to receive treatment with both materials, one in each nasolabial fold. Patients returned at 2-week intervals for further treatment until both sides of the face reached optimal correction. The average number of treatment sessions required to achieve this optimal result was 1.4 for both products. The volume needed for correction was lower with Restylane ${ }^{\circledR}$ (mean $1.0 \mathrm{~mL}$; range $0.3-2.8 \mathrm{~mL}$ ) than for Zyplast ${ }^{\circledR}$ (mean $1.6 \mathrm{~mL}$; range 0.1-5.0 mL). The Wrinkle Severity Rating Scale score for Restylane ${ }^{\circledR}$ was superior at all time points $(2,4$, and 6 months after baseline), and at 6 months after baseline: Restylane ${ }^{\circledR}$ was rated superior in $56.9 \%$ of patients compared with Zyplast ${ }^{\circledR}$, in $9.5 \%$ of patients. The Global Aesthetic Improvement Scale rating was also superior for Restylane ${ }^{\circledR}$ at all time points, with $62 \%$ rating Restylane ${ }^{\circledR}$ superior at 6 months compared with Zyplast ${ }^{\circledR}$, with only $8 \%$ rating Zyplast ${ }^{\circledR}$ superior to Restylane $^{\circledR}$.

Adverse events were recorded at each time visit during the clinical study. Mild or moderate injection site reactions occurred in a similar non-statistical fashion with both of the injectable projects $\left(93.5 \%\right.$ with Restylane ${ }^{\circledR}$ and $90.6 \%$ with Zyplast $\left.{ }^{\circledR}\right)$. During the 6 month follow-up period, treatment-related adverse events were reported to be $26.4 \%$ for Restylane ${ }^{\circledR}$ and $39.1 \%$ for Zyplast ${ }^{\circledR}$. Delayed-onset reactions were noted in $8.7 \%$ of patients - all resolved within 2-3 months without treatment. No hypersensitivity reactions were reported during the clinical trial.
Restylane ${ }^{\circledR}$ has been used for the past several years by numerous injectors with very acceptable clinical results. Most would agree that Restylane ${ }^{\circledR}$ is injected easily through small-gauge (30 gauge) needles, with mild local injection-site reactions and pain during the injection process being its major concerns. Restylane ${ }^{\circledR}$ does last longer than Zyplast ${ }^{\circledR}$ collagen, with most feeling correction can be maintained from 6 to 12 months. Restylane ${ }^{\circledR}$ Perlane ${ }^{\circledR}$ has finished FDA clinical trials and is awaiting FDA approval at the time of this writing. Restylane ${ }^{\circledR}$ Fine Lines will appear in the future as well. Clinical examples of the use of Restylane ${ }^{\circledR}$ are seen in Figures 3 and 4.

\section{Juvederm ${ }^{\text {TM }}$}

The last of the HA fillers currently available is known as Juvederm $^{\mathrm{TM}}$. It is manufactured by Lea Derm, a subsidiary of Corneal Group (Paris, France). It was developed in the US by Inamed $^{\circledR}$ (Santa Barbara, CA, US) and currently is marketed by Allergan, Inc. (Irvine, CA, US). Two current formulations of Juvederm $^{\mathrm{TM}}$ are available in the US - Juvederm ${ }^{\mathrm{TM}}$ Ultra and Juvederm $^{\text {TM }}$ Ultra Plus. Six different formulations of Juvederm $^{\mathrm{TM}}$ have been developed, with differing concentrations of HA in each formulation, ranging from $18 \mathrm{mg} / \mathrm{g}$ to $30 \mathrm{mg} / \mathrm{g}$. The two available US products contain 24 and $30 \mathrm{mg} / \mathrm{g}$ of HA, respectively, and are known as high
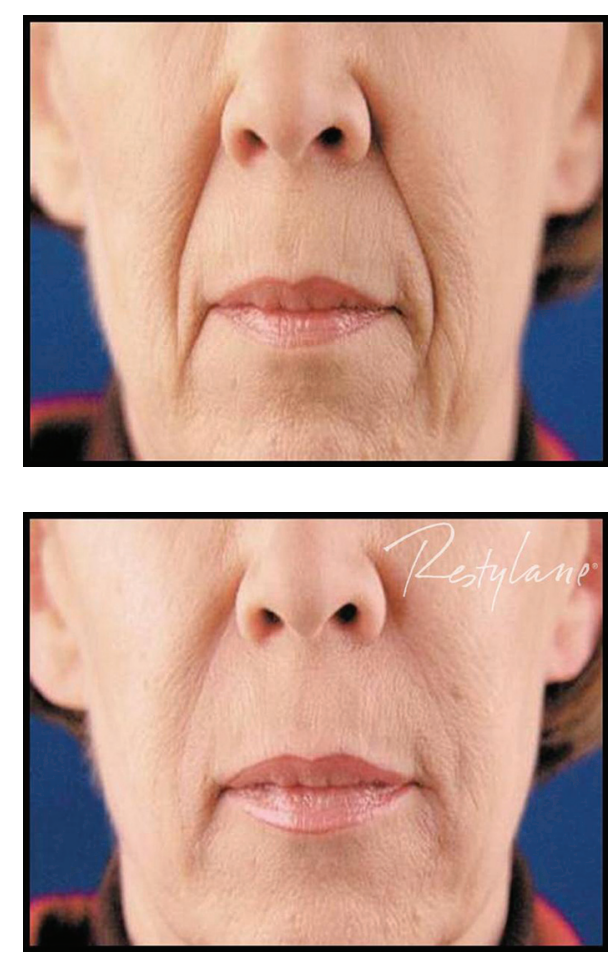

Figure 3 A clinical example of the use of Restylane ${ }^{\circledR}$ for nasolabial folds. 

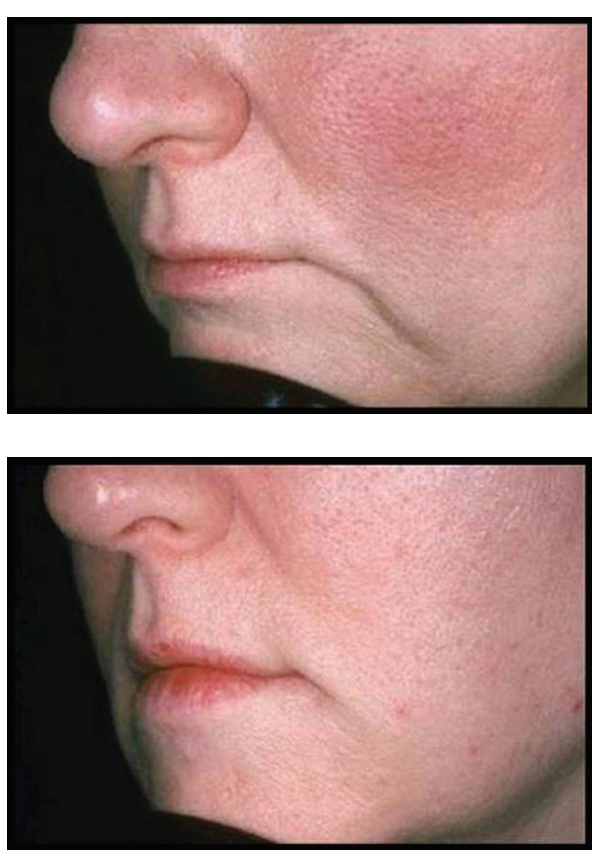

Figure 4 A clinical example of the use of Restylane ${ }^{\circledast}$ for nasolabial folds.

viscosity HA fillers. They were FDA approved in June, 2006 - Juvederm ${ }^{\mathrm{TM}}$ Ultra for deep wrinkles and defects, Juvederm $^{\text {TM }}$ Ultra Plus for deeper furrows, such as the nasolabial folds. The Juvederm ${ }^{\mathrm{TM}}$ family is produced from the bacterial fermentation of equine streptococci. The HA is cross-linked with a patented single-phase BDDE-phosphate buffered to 6.5-7.3 pH. With a higher concentration of HA and more cross-linking than other HA fillers, it is felt by some injectors that perhaps the Juvederm ${ }^{\mathrm{TM}}$ family of products may persist longer than other HA fillers and have a more smooth injection flow (Medical Insight Inc 2006), although clinical studies documenting these claims have not been performed in a head-to-head comparison against any of the other available HA fillers.

The pivotal US clinical trial, by Baumann et al (2006), was a comparison of Juvederm ${ }^{\mathrm{TM}}$ products with Zyplast ${ }^{\mathrm{TM}}$ collagen in the treatment of nasolabial folds. Four hundred and twenty-three patients completed the clinical trial of a 24-week evaluation. Over three hundred of the patients received an additional treatment of the HA filler at the conclusion of the clinical trial which looked at long-term efficacy. Results showed that both of the fillers used showed significant improvements at all points during the course of the 24-week clinical trial. The Juvederm ${ }^{\mathrm{TM}}$ products studied showed significantly greater efficacy than the bovine collagen product; the efficacy increased with time and was greatest at 24 weeks after the last treatment. Utilizing a 4 point scale, an improvement of at least 1 point was seen in more than $80 \%$ of Juvederm ${ }^{\mathrm{TM}}$-treated patients compared with a 0.5 improvement, on average, in the Zyplast ${ }^{\mathrm{TM}}$-treated patients. For those having an end of 24 week injection, long-term results showed that $57 \%$ had duration of effect at 8 months, $37 \%$ at 10 months, and $18 \%$ at 12 months.

Adverse events were similar in this pivotal trial for both the Juvederm ${ }^{\mathrm{TM}}$ and Zyplast $^{\mathrm{TM}}$ sides that were treated. Mild to moderate treatment site reactions were seen in most patients; all resolved within 7 days. No long-term adverse reactions were noted. Patient preference data suggested a $78 \%$ preference with Juvederm ${ }^{\text {TM }} 30,88 \%$ with Juvederm ${ }^{\text {TM }}$ $24 \mathrm{HV}$, and $84 \%$ with Juvederm ${ }^{\mathrm{TM}} 30 \mathrm{HV}$. From this clinical study, Juvederm ${ }^{\mathrm{TM}} 24 \mathrm{HV}$ and Juvederm ${ }^{\mathrm{TM}} 30 \mathrm{HV}$ were chosen for the US market.

Most clinicians utilizing Juvederm ${ }^{\mathrm{TM}}$ will note that it does inject easily through the syringe and that results between 6 and 12 months are commonly observed. Local injection site reactions are rare and there has been some discussion that the injection of Juvederm ${ }^{\mathrm{TM}}$ results in a more natural appearance than the other HA fillers, although no clinical studies with regard to this debate have been performed. Clinical examples of Juvederm $^{\mathrm{TM}}$ are seen in Figures 5 and 6.

\section{Puragen $^{\mathrm{TM}}$ and Puragen ${ }^{\mathrm{TM}}$ Plus}

Other HA fillers are in development in the US and should receive FDA clearance over the next several years. Mentor Corporation (Santa Barbara, CA, US) is primed to launch
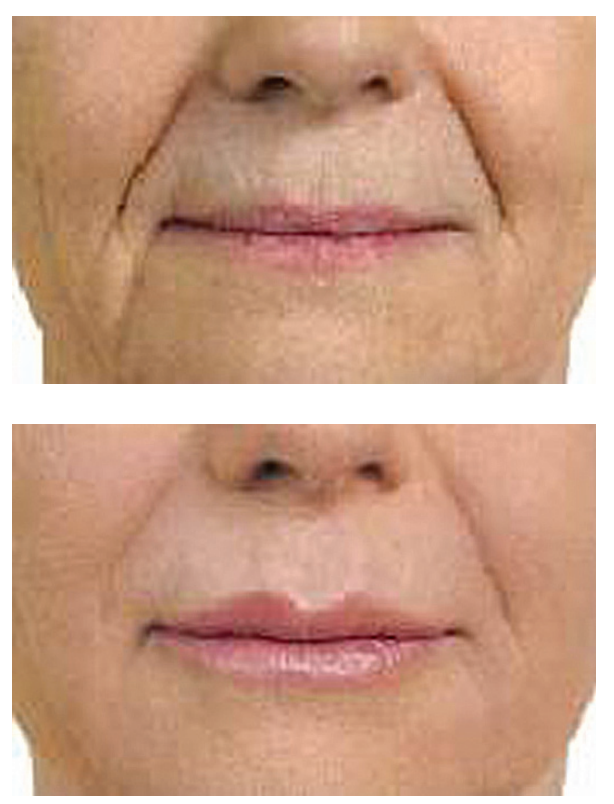

Figure 5 A clinical example of the use of Juvederm ${ }^{\mathrm{TM}}$ for nasolabial folds. 

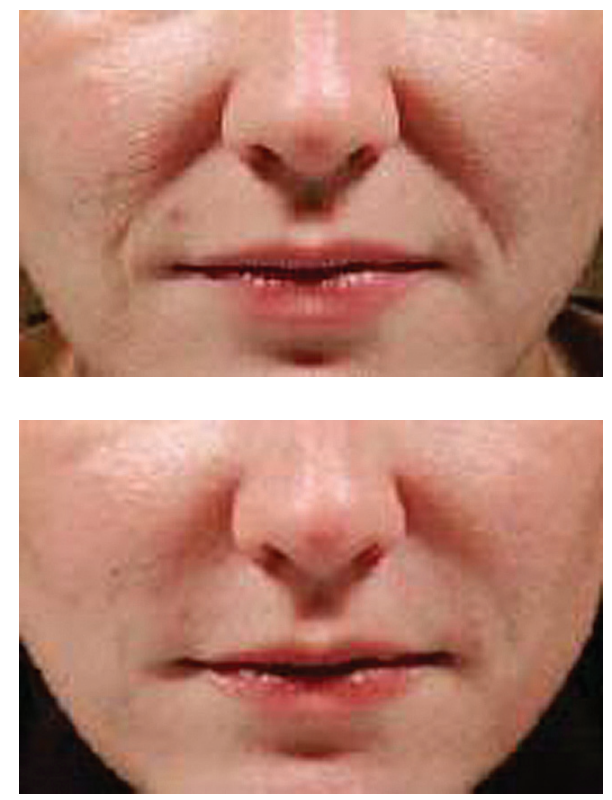

Figure 6 A clinical example of the use of Juvederm ${ }^{\text {TM }}$ for nasolabial folds.

Puragen $^{\text {TM }}$ Plus in the US. Puragen ${ }^{\mathrm{TM}}$ is currently available in Europe. Both Puragen ${ }^{\mathrm{TM}}$ and Puragen ${ }^{\mathrm{TM}}$ Plus, the first HA filler with lidocaine added, are double cross-linked, which may prove of value in increasing the resistance to the degradation of the HA filler. They are both non-animal derived HA fillers (Medical Insight Inc 2006). Puragen ${ }^{\mathrm{TM}}$ Plus contains $20 \mathrm{mg} / \mathrm{g}$ HA and its pivotal clinical trial was the first in the US to evaluate one HA filler, in this case Puragen ${ }^{\mathrm{TM}}$ Plus, versus Restylane ${ }^{\circledR}$ in the other nasolabial fold. Clinical trial results are not yet available but the European experience shows that this filler probably lasts from 6 to 12 months. Local adverse reactions, similar to those of the other HA fillers, have been noted as well. The addition of lidocaine gives Puragen ${ }^{\mathrm{TM}}$ Plus its hook that is its differentiator and only time will tell whether it will be of clinical significance. Clinical examples of Puragen ${ }^{\mathrm{TM}}$ are shown in Figures 7 and 8.

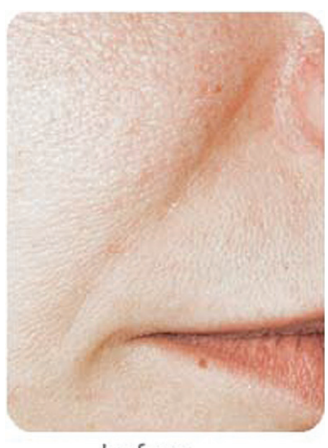

before

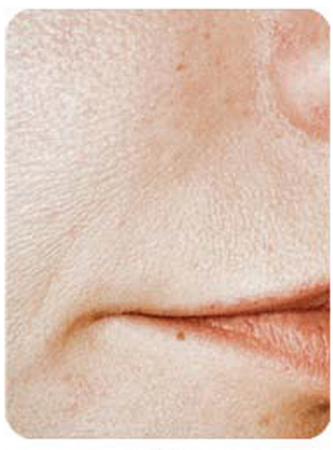

after
Figure 7 A clinical example of the use of Puragen ${ }^{\mathrm{TM}}$ for nasolabial folds.

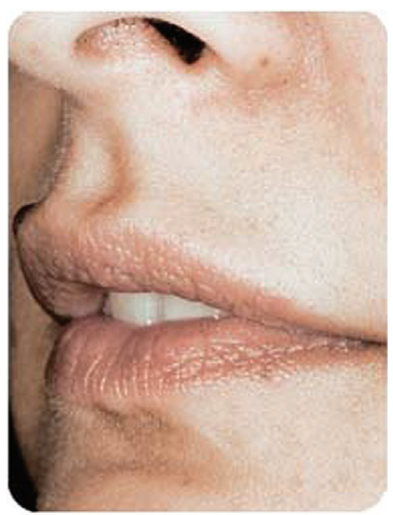

before

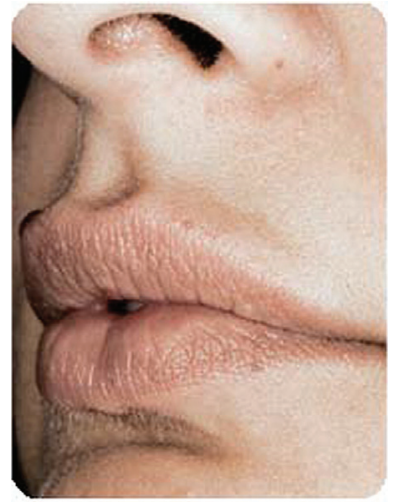

after
Figure $8 \mathrm{~A}$ clinical example of the use of Puragen ${ }^{\mathrm{TM}}$ for lip augmentation.

\section{Belotero}

The other HA filler currently being investigated is known as Belotero, manufactured by Merz Pharmaceuticals (Germany, Raleigh, NC, US). It is a non-animal, monophasic cross-linked gel. It utilizes $22.5 \mathrm{mg} / \mathrm{mL} \mathrm{HA}$ in a patented matrix technology. It is also undergoing clinical testing in the US market.

Other HA fillers will also be coming to the US over the next several years. There are numerous of these products available in Europe and looking for a home in the US. Most of the major pharmaceutical companies are looking to partner with these European companies and to bring their technology into the aesthetic US market. We, as physicians, will have many options for fillers in the near future. This is good for physicians, as the prices for these fillers should become more reasonable, and better for their patients, where optimal fillers can be utilized for the many needs and defects for which they can be utilized.

Currently, physicians have a choice of only a handful of HA fillers available for use for these patients. Most of our patients are familiar with Restylane ${ }^{\circledR}$ and it is currently the treatment of choice for most patients. Skilled injectors will offer patients either Restylane ${ }^{\circledR}$ or one of the Juvaderm ${ }^{\mathrm{TM}}$ products, and it would be up to the injector to determine which of the HA fillers they feel most comfortable injecting. Head-to-head comparison studies are lacking at this time. These types of studies would give physicians a better understanding of which HA filler works best for which patient and where each HA filler works better. Without these studies, it is physician preference and patient preference as to which products are used for patients.

\section{Disclosures}

Dr. Gold is a consultant for Mentor Corporation, speaks on their behalf and performs research. Dr. Gold performs 
research for Allergan Inc. as well as Medicis, and a consultant for Medicis.

\section{References}

Alberts B, Johnson A, Lewis J, et al. (eds). 2002. The molecular biology of the cell. Cell junctions, cell adhesion, and the extracellular matrix. 1065. New York: Garland Science.

Balazs EA, Denlinger JL. 1989. Clinical uses of hyaluronan. Ciba Found Symp, 143:265.

Baumann LS, Shamban AT, Lupo, MP, et al. 2006. Comparison of hyaluronic acid-based fillers with crosslinked bovine collagen: a doublemasked, multicenter, randomized, within-subject study [poster]. AAD Poster Presentation.

Duranti F, Salti G, Bovani B, et al. 1998. Injectable hyaluronic acid gel for soft tissue augmentation: a clinical and histologic study. Dermatol Surg, 24:1317.

Eppley BL, Dadvand B. 2006. Injectable soft-tissue fillers: clinical overview. Plast and Reconst Surg, 118:98e-106e.

Friedman PM, Mafong EA, Kauvar ANB, et al. 2002. Safety data of injectable nonanimal stabilized hyaluronic acid gel for soft tissue augmentation. Dermatol Surg, 28:491.

Lowe NJ, Maxwell CA, Lowe P, et al. 2001. Hyaluronic acid skin fillers: adverse reactions and skin testing. J Am Acad Dermatol, 45:930.
Lupton JR, Alster TS. Cutaneous hypersensitivity reaction to injectable hyaluronic acid. Dermatol Surg, 26: 2000; 135.

Manna F, Dentini M, Desideri P, et al. 1999. Comparative chemical evaluation of two commercially available hyaluronic acids used for soft tissue augmentation. J Eur Acad Dermatol Venereol, 13:183.

Matarasso SL, Carruthers JD, Jewell ML, et al. 2006. Consensus recommendations for soft-tissue augmentation with nonanimal stabilized hyaluronic acid (Restylane ${ }^{\circledR}$ ). Plast Reconst Surg, 117(Suppl):3s-34s.

Medical Insight, Inc. 2006. Global market for dermal fillers 2005-2011.

Mentor Corporation. 2006. Product Information Sheet on CosmoDerm ${ }^{\circledR}$ and CosmoPlast $^{\circledR}$. Santa Barbara, Calif.

Micheels P. Human anti-hyaluronic acid antibodies: is it possible? Dermatol Surg, 27:185.

Monheit GD. 2004. Hylaform ${ }^{\circledR}$ : a new injectable hyaluronic acid filler. Facial Plast Surg, 20:153.

Narins RS, Bowman PH. 2005. Injectable skin fillers. Clin Plast Surg, 32:151-62.

Narins RS, Brandt F, Leyden J, et al. 2003. A randomized, double-blind, multicenter comparison of the efficacy and tolerability of Restylane ${ }^{\circledR}$ versus Zyplast $^{\circledR}$ for the correction of nasolabial folds. Dermatol Surg, 29:588.

Olenius M. 1998. The first clinical study using a new biodegradable implant for the treatment of the lips, wrinkles, and folds. Aesthet Plast Surg, 22:97. 